\title{
Os diferentes tipos de abordagem de um laboratório em matemática e suas contribuições para a formação de professores
}

\author{
The different types of approach of a laboratory in mathematics and your contributions \\ for teacher training
}

\author{
Fredy Coelho Rodrigues ${ }^{1}$ \\ fredy.rodrigues@ifsuldeminas.edu.br
}

\author{
Eliane Scheid Gazire ${ }^{2}$ \\ egazire@terra.com.br
}

\begin{abstract}
Resumo
Laboratórios ligados ao ensino e aprendizagem da matemática tem sido o objeto de estudo de várias pesquisas em Educação Matemática. Nestes estudos não há nenhuma tentativa em caracterizar e diferenciar os diferentes tipos de laboratório que vem sendo utilizados na formação de professores em matemática. Diante desse contexto, este trabalho se propôs então a investigar os vários tipos (concepções) de laboratório utilizados na formação de professores em Matemática, em razão dos seus diferentes objetivos e propostas de utilização encontradas na literatura. Para o desenvolvimento deste trabalho realizou-se uma pesquisa bibliográfica, do tipo metanálise, com o objetivo de identificar e comparar os diferentes tipos de laboratório ligados à Matemática bem como descrever o foco de atuação de cada um deles e suas contribuições para formação de professores. Como resultado deste trabalho destaca-se a criação de sete categorias para classificar os laboratórios de matemática atualmente utilizados na formação de professores. Entre todas as tipificações propostas e com base na descrição de cada uma delas, o estudo sugere que o laboratório denominado por "Agente de Formação" oferece maiores contribuições para a formação de professores em Matemática.
\end{abstract}

Palavras-chave: Formação de professores. Laboratório de Matemática. Laboratório de Ensino de Matemática. Laboratório de Educação Matemática.

\begin{abstract}
Laboratories involved in teaching and learning mathematics has been studied by several research in mathematics education. In these studies there is no attempt to characterize and differentiate the different types of laboratory that has been used in the training of mathematics teachers. In this context, this work is then proposed to investigate the various types (designs) laboratory used in teacher training in mathematics, because of their different objectives and use of proposals found in the literature. To develop this work we carried out a literature search, the meta-analysis type, in order to identify and compare the different types of laboratory related to Mathematics and describe the focus of activity of each of them and their contributions to teacher training. As a result of this study highlight the creation of seven categories to classify mathematics laboratories currently used
\end{abstract}

\footnotetext{
${ }^{1}$ Professor do Ensino Básico Técnico Tecnológico do IFSULDEMINAS, campus Passos. Atua na licenciatura em Matemática. Possui mestrado em Ensino de Ciências e Matemática - PUC Minas.

${ }^{2}$ Professora e Coordenadora do Mestrado de Ensino de Ciências e Matemática da PUC Minas.
} 
in teacher education. Among all typifications proposals and based on the description of each of them, the study suggests that the lab called for "Training Agent" offers greater contributions to teacher training in Mathematics.

Keywords: Training of teachers. Laboratory of Mathematics. Laboratory for Teaching Mathematics. Mathematics Education Laboratory.

\section{Introdução}

Laboratórios ligados ao ensino aprendizagem da Matemática têm sido objetos de estudo de várias pesquisas ${ }^{3}$ em Educação Matemática. Nestas pesquisas, muito se tem discutido sobre as diferentes concepções de laboratório, os objetivos, o papel e a importância deste na formação de professores, bem como as diferentes propostas de sua utilização nas diversas instituições de Ensino Superior comprometidas com a formação de professores.

A importância dada ao assunto foi ampliada após a LNDBE, de 20.12.1996 e da CNE/CP n²2, de 19.02.2002 determinarem a obrigatoriedade de 400 horas de estágio supervisionado na matriz curricular dos cursos de Licenciatura (VARIZO, 2007). Em virtude disso, muitas instituições de Ensino Superior passaram a sentir a necessidade de criar ambientes que pudessem dar suporte ao planejamento das atividades de estágio, como também favorecer a realização da prática pedagógica das disciplinas do núcleo pedagógico destas Licenciaturas.

Nesse contexto, inúmeros cursos de Licenciatura em Matemática espalhados pelo Brasil começaram a implantar os seus laboratórios. Entretanto, as funções deste laboratório e seu vínculo em cada uma destas instituições têm sido diferentes (VARIZO, 2007), sendo alguns vinculados às Faculdades de Educação e outros aos institutos da área de Ciências Exatas. Segundo Varizo (2007):

A maioria está voltada para questões pedagógicas da Matemática no Ensino Básico (EB), alguns se dedicam ao ensino da Matemática na universidade, outros priorizam uma única disciplina e poucos se destinam só a pesquisa. Quanto ao foco da formação docente, uns visam à formação inicial e continuada de professores de Matemática, outros enfatizam apenas uma delas. (VARIZO, 2007, p.1-2).

De acordo com Lorenzato (2006), muitos destes laboratórios possuem diferentes propostas de utilização, umas mais teóricas, outras mais práticas, algumas em tecnologia da informação e

\footnotetext{
${ }^{3}$ Lorenzato (2006), Rêgo \& Rêgo (2006), Turrioni e Perez (2006), Passos (2006), Scheffer (2006), Kaleff (2006), Bertoni e Gaspar (2006), Miskulin (2006), Varizo (2007), Benini (2006), Aguiar (1999), Oliveira (1983), Lopes e Araújo (2007), Turrioni (2004).
} 
comunicação e outras não. O autor revela que, diante dessa variedade de concepções, destacase a importância do papel professor como um agente mediador na construção de um conhecimento significativo.

No quadro teórico indicado acima, existe uma discussão bem ampla a respeito dos diferentes tipos de laboratório que vêm sendo utilizados na formação de professores em Matemática. No entanto, toda essa discussão até o momento não se preocupou em categorizar/nomear os diferentes tipos de laboratório com base em seus diferentes objetivos, focos de atuação e propostas de utilização. Em alguns destes trabalhos, concepções ou tipos de laboratório se confundem uns com os outros pelo fato de não haver distinção clara dos seus diferentes objetivos e propostas de uso.

Nesse contexto, este estudo se justifica na medida em que pretende investigar, de forma mais criteriosa, a utilização dos laboratórios ligados à Matemática, objetivando, assim, a criação de categorias que possam nomear e classificar os diferentes tipos de laboratório em Matemática descritos na literatura tendo em vista os seus diferentes objetivos e propostas de utilização. Em cada categoria de laboratório proposta pelos autores pesquisados, pretendeu-se descrever o foco de atuação e formação, o papel do professor diante dessa concepção de laboratório, bem como o seu objetivo e suas contribuições para a formação de professores.

\section{Metodologia}

Para o desenvolvimento dessa pesquisa realizou-se uma pesquisa bibliográfica do tipo metanálise, com foco na abordagem qualitativa, objetivando categorizar os diferentes tipos de laboratório ligados à Matemática.

O estudo bibliográfico caracterizado pelo tipo metanálise, é descrito por Fiorentini e Lorenzato (2006) como “[...] uma revisão sistemática de outras pesquisas, visando realizar uma avaliação crítica das mesmas e/ou produzir novos resultados ou sínteses a partir do confronto desses estudos, transcendendo aqueles anteriormente obtidos". (FIORENTINI; LORENZATO, 2006, p.103).

Para a realização deste estudo, para tanto, foram consultados: artigos, relatos de experiência, livro, dissertações e teses pertencentes à literatura nacional, publicados até o final de fevereiro de 2011. O critério adotado para a seleção destas referências bibliográficas se deu por meio da 
busca das seguintes palavras-chave na base de dados do Google acadêmico: Laboratório de matemática, experimentação em laboratório, laboratório de ciências, laboratório de ensino de matemática, laboratório de educação matemática, objetivos do laboratório de ensino de matemática, utilização do laboratório de ensino/educação matemática na formação de professores, materiais didáticos manipuláveis, concepções de laboratório.

Durante a realização da pesquisa bibliográfica, a coleta de dados foi feita a partir do fichamento do material bibliográfico levantado. O recurso do fichamento foi utilizado, uma vez que, segundo Fiorentini e Lorenzato (2006), este recurso vem auxiliar o pesquisador a organizar de maneira mais sistemática os dados da pesquisa. No fichamento, visando facilitar o processo de categorização (tipos de laboratório), os pesquisadores procuraram analisar em cada referência os seguintes itens:

- Concepção de laboratório presente.

- Caracterização deste laboratório com base no foco de formação: formação inicial ou continuada.

- Objetivo/papel do laboratório.

- Atividades desenvolvidas.

- Proposta de utilização.

- Papel do professor e do aluno frente a essa concepção de laboratório.

- Como era realizada a utilização de material didático neste laboratório.

A metodologia da análise de conteúdo (metanálise) realizada sobre o material consultado permitiu que as categorias referentes aos tipos de laboratório fossem surgindo a partir das informações principais mais recorrentes e mais distintas que foram emergindo dos dados coletados a partir dos itens destacados anteriormente. Dessa forma, foi possível criar as seguintes categorias relacionadas aos vários tipos de laboratório:

1) Laboratório/Depósito-arquivo

2) Laboratório/ Sala de aula

3) Laboratório/ Disciplina 
4) Laboratório/ Laboratório de Tecnologia

5) Laboratório/ Tradicional - Laboratório de Matemática

6) Laboratório/ Sala Ambiente - Laboratório de Ensino de Matemática

7) Laboratório/ Agente de formação - Laboratório de Educação Matemática

A descrição de cada categoria (tipos de laboratório) constituiu os resultados deste trabalho. Em cada tipo de laboratório identificado, realizou-se a caracterização do mesmo, de modo a apontar as contribuições e o foco de atuação para cada laboratório na formação de professores.

\section{Resultados/Discussão: Os diferentes tipos de abordagem do laboratório em Matemática.}

\section{1) Laboratório/ Depósito-arquivo}

Numa classificação de modalidades, este laboratório ocupa o nível mais baixo em relação ao tipo de envolvimento que poderia haver entre professores e alunos dentro do seu próprio espaço físico. A explicação para isso se revela na medida em que o seu espaço físico é entendido apenas como um lugar, um depósito de materiais que deverá servir de apoio, em especial ao professor, para a realização de suas atividades práticas fora desse ambiente.

Nesse sentido, encontramos em Lorenzato (2006) uma definição para este laboratório:

[...] um local para guardar materiais essenciais, tornando-os acessíveis para as aulas; neste caso, é um depósito/arquivo de instrumentos, tais como: livros, materiais manipuláveis, transparências, filmes, entre outros, inclusive matérias-primas e instrumentos para confeccionar materiais didáticos. (LORENZATO, 2006, p.6).

Prioriza-se, nessa descrição, o que Benini (2006) considera como "aspecto funcional" em relação ao objetivo desse laboratório, ou seja, oferecer uma infraestrutura necessária que possa abrigar e dar acesso os materiais didáticos que irão facilitar a tarefa do professor no processo ensino-aprendizagem.

Lorenzato (2006) juntamente com Turrioni (2004) admitem que, na ausência deste espaço físico numa instituição de Ensino Superior, nada impede que este laboratório aconteça sob a forma de um laboratório móvel, ou seja, dentro de uma caixa que pode ser transportada, ou 
mesmo no porta-malas de um carro. Porém, ainda nesse caso, tanto o objetivo como o seu papel ainda continuam sendo os mesmos de um Laboratório Depósito-Arquivo.

De modo geral, a utilização deste laboratório se assemelha muito ao uso de uma biblioteca, pelo fato de poder oferecer aos professores e alunos o acesso aos materiais que possibilitam a construção do conhecimento. Isso acontece à medida que ele disponibiliza aos seus usuários um acervo de livros e materiais didáticos diversificados que irão contribuir para o desenvolvimento das atividades práticas. Dessa forma, o nome Laboratório Biblioteca também poderia ilustrar essa concepção ou tipo de laboratório.

\section{2) Laboratório/ Sala de aula}

Segundo Aguiar (1999), o ambiente da sala de aula pode ser pensado e entendido como um tipo de laboratório, uma vez que muitas experiências que ocorrem nesse lugar não necessitam que o mesmo esteja abarrotado de materiais didáticos. Muitas dessas experiências "ocorrem no campo das ideias, no uso da imaginação e provocam discussões, investigações e pesquisas." (AGUIAR, 1999, p.144). Nesse sentido, cabe ao professor orientar e mediar essas discussões/reflexões, de modo que as experiências individuais de cada aluno possam surgir e resultar em uma aprendizagem significativa.

Para alguns professores que são adeptos dessa concepção de laboratório, o ambiente da sala de aula, como também todas as suas aulas de Matemática, também pode se transformar num importante espaço (laboratório) para o aluno descobrir essa Ciência de uma maneira informal, por meio da realização de atividades práticas com material manipulável ou pela vivência de metodologias alternativas (REFOSCO; BASSOL, 2007). Ao fazer uso de material concreto em sala de aula, o professor estará utilizando uma abordagem de laboratório que, segundo Tahan (1962), recebe o nome de "método do laboratório". Através da aplicação desse método, o ensino da Matemática é apresentado "ao vivo" pelo professor aos seus alunos, com o auxilio de material concreto para ilustrar e demonstrar alguns conceitos de Matemática, de uma forma diferente e divertida (TAHAN, 1962).

\section{3) Laboratório/ Disciplina}

Como disciplina do curso de Licenciatura em Matemática, este componente curricular poderá estar "voltado para o conhecimento e uso de um laboratório no ensino e aprendizagem da 
Matemática" (BERTONI; GASPAR, 2006, p.137), como também "integrar a pesquisa no projeto de formação inicial do educador matemático" (PIRES, 2008).

Nesse sentido, de acordo com o autor, esta disciplina poderá tratar os conteúdos da Educação Básica através de "oficinas e micro-aulas, por meio da pesquisa, de estudo, de manipulação e de confecção de materiais didáticos e de jogos, com ênfase nos tratamento dos porquês matemáticos e na formação do educador-pesquisador”. (PIRES, 2008, p.9).

Ao considerar o laboratório como uma disciplina, portanto, o mesmo passa a ter uma ementa que, na maioria das vezes, propõe a discussão de assuntos relativos à Educação Matemática. Entretanto, essa concepção teórica de laboratório necessita de um espaço físico para a realização da prática pedagógica. Quando isso acontece, é preciso que os objetivos instrucionais e epistemológicos da disciplina sejam privilegiados em detrimento do objetivo funcional ligado à estrutura física deste laboratório. Nesse caso, a disciplina laboratório possui uma concepção teórico-prática. (LORENZATO, 2006; BENINI, 2006).

\section{4) Laboratório/ Laboratório de Tecnologia}

A ideia do Laboratório de Tecnologia descrita aqui vai desde a sua concepção mais simples, como Laboratório de Informática, a uma concepção mais ampla proposta por Miskulin (2006).

Na concepção mais redutora (Laboratório de Informática), o Laboratório de Tecnologia pode ser entendido como um espaço, com computadores, por meio dos quais poderão ser feitas pesquisas e visitas em sites da internet. Além disso, este laboratório também pode ser considerado como um espaço onde os conceitos matemáticos possam ser explorados por meio de um software dinâmico, havendo sempre a mediação do professor. Através desse software dinâmico, conceitos de matemática podem se explorados e discutidos através de animações e simulações a partir dos quais a visualização vem permitir o estabelecimento de relações e propriedades que podem ser verificadas diretamente na tela do computador (SCHEFFER, 2006). 
Já sob uma visão mais ampla, o laboratório de tecnologia mediado pelo computador é concebido como algo que vai muito além do espaço físico, constituindo-se num ambiente com dimensão infra-estrutural e dimensão conceitual.

A dimensão infra-estrutural envolve o espaço físico do laboratório em si, com todo o suporte técnico de computadores e softwares disponíveis para a produção de mídias que serão disponibilizadas em um ambiente online a serviço da educação à distância. Já a dimensão conceitual relaciona-se a uma concepção didático-pedagógica, sendo considerada "um cenário de aprendizagem colaborativa e de conhecimento compartilhado, um espaço de formação, apoiado numa abordagem teórico-metodológica e conduzida pela mediação do professor/pesquisador”. (MISKULIN, 2006, p.163).

Nessa concepção mais ampla do laboratório de tecnologia, a autora considera o ambiente de aprendizagem colaborativa como:

\footnotetext{
Um cenário que pressupõe ambientes computacionais ou softwares educativos e metodologias nas quais a comunicação se realiza de forma dinâmica entre várias pessoas, com independência de ritmo, e em que a aprendizagem pode aparecer em qualquer tempo e em qualquer lugar, estando implícito um processo de interatividade total entre os vários participantes. (MISKULIN, 2006, p.164).
}

Nunes, Souza e Dandolini (2005) consideram que o objetivo desse laboratório visa atender as necessidades do curso de formação de professores na modalidade de ensino à distância. Dentro dessa proposta de laboratório, o aluno não produz material didático. O professor responsável pela disciplina, cujas atividades são disponibilizadas online, juntamente com a equipe pedagógica que dá suporte é quem serão os responsáveis pela confecção dos materiais que serão disponibilizados nesse curso à distância (NUNES; SOUZA; DANDOLINI, 2005, p.3).

Segundo SOLETIC (2001), uma das grandes dificuldades enfrentadas pela educação à distância está na comunicação professor-aluno que não acontece face a face. Quando isso não acontece, o aluno fica impossibilitado de obter resposta ao seu questionamento no momento em que ele está frente a uma atividade proposta na plataforma de ensino (SOLETIC, 2001). 


\section{5) Laboratório/ Tradicional - Laboratório de Matemática}

De acordo com Benini (2006, p.48), é difícil estabelecer regras rígidas para determinar o que é e o que não é um laboratório tradicional. No entanto, a autora explica que, ao analisar como os estudantes de várias outras áreas da Ciência se "desenvolvem" durante a realização de atividades práticas dentro da sua própria área de formação profissional, foi possível encontrar alguns pontos em comum a partir dos quais se tornou possível traçar, grosso modo, os seguintes objetivos para este laboratório:

Habilitar os estudantes no manuseio de instrumentos de medidas; realizar experimentos como o intuito de verificar leis e fenômenos; motivar os estudantes para o estudo da disciplina em questão; dar suporte aos cursos teóricos da disciplina estudada e introduzir os alunos no método científico. (BENINI, 2006, p.48).

Nessa concepção de laboratório, com ênfase no procedimento ${ }^{4}$, Passos $(2006 ; 2007)$ revela que a aquisição do conhecimento começa pela crença do professor de que a observação empírica e a manipulação do material por parte do aluno, possibilitada pelos órgãos de sentido, possam produzir neste impressões que o levem à construção de conceitos que são extraídos diretamente do material manipulado. Esse apego ao material como um fim em si é um forte traço do laboratório tradicional.

Os experimentos, realizados no ambiente deste laboratório, visam reconstituir fenômenos, demonstrar leis e verificar propriedades a partir do material concreto ali existente; pretende, também, motivar os alunos, podendo, ainda, desenvolver nestes outras habilidades menos recorrentes do que as habilidades procedimentais, como, por exemplo, as habilidades de processo $^{5}$ (MILLAR; DRIVER, 1987, citados por LABURÚ, 2005) e as habilidades de atitude $^{6}$ (TRUMPER, 2003, p.649, citado por LABURÚ, 2005).

\footnotetext{
${ }^{4} \mathrm{O}$ procedimento será entendido neste trabalho como uma sequencia pré-estabelecida de instruções para o desenvolvimento de experimentos tendo como referência o modelo de método científico.

${ }^{5}$ A habilidade de processo será entendida neste trabalho como uma habilidade cognitiva de reunir informações científicas, organizar ou impor uma ordem intelectual sobre os dados, de forma a reconhecer regularidades, interpretar, elaborar e testar hipóteses, extrair conclusões e fazer inferências de dados e observações, indagar questões científicas, assegurando as respostas via experimento, desenvolver o pensamento lógico e crítico, [...] saber transpor o raciocínio concreto e a linguagem verbal para uma linguagem e um raciocínio matemático mais abstrato e vice-versa.

${ }^{6}$ A habilidade de atitude será entendida como a habilidade que envolve a aptidão para a aprendizagem colaborativa, trabalhar em cooperação, participar da distribuição e conjugação de tarefas, compartilhar resultados com outras equipes, respeitar e comparar ideias opostas às das pessoas etc..
} 
Entretanto, a ênfase no procedimento dado a este Laboratório Tradicional (Matemática) limita o poder de decisão do aluno, uma vez que este, ao seguir os passos de um roteiro prescrito pelo professor, durante o desenvolvimento de uma experiência, é levado a tirar conclusões já conhecidas e estabelecidas. Neste contexto, esse aluno não tem liberdade de pensar ou tentar novas estratégias, uma vez que a sua maneira de pensar e agir é conduzida por um roteiro programado pelo professor (BENINI, 2006).

Assim, o laboratório tradicional vem a se constituir num espaço para introduzir os alunos na experiência e vivência das etapas que compõem o método científico. É neste lugar, diferente do ambiente da sala de aula convencional, que o professor de Matemática dispõe de toda uma infraestrutura preparada para o desenvolvimento de experiências com materiais didáticos.

De acordo com Benini (2006), o papel do professor neste laboratório consiste em supervisionar e auxiliar a realização de experimentos, e, mais especificamente, estabelecer os passos que o aluno deverá seguir para o desenvolvimento dessas atividades, a fim de que se possa chegar ao resultado esperado.

\section{6) Laboratório/ Sala Ambiente - Laboratório de Ensino de Matemática}

Este tipo de laboratório tem, como foco central, a realização de atividades de ensino com ênfase na vivência de processos que auxiliam a construção do conhecimento matemático, bem como a realização de atividades que promovam o desenvolvimento de atitudes nos alunos.

Para Lorenzato (2006), o Laboratório de Ensino de Matemática é definido como:

Uma sala-ambiente para estruturar, organizar, planejar e fazer acontecer o pensar matemático, é um espaço para facilitar, tanto ao aluno como ao professor, questionar, conjecturar, procurar, experimentar, analisar e concluir, enfim, aprender e principalmente aprender a aprender. (LORENZATO, 2006, p.7).

Nessa descrição do Laboratório de Ensino de Matemática como sala ambiente, percebe-se que a ideia proposta por este autor não fica somente restrita ao lugar; inclui, também, todo o desenvolvimento de um processo que antecede a construção do conhecimento matemático.

É neste ambiente, que o professor poderá aguçar a curiosidade dos alunos, promover discussões, reflexões, realizar atividades experimentais e investigações, bem como 
problematizar situações e conceitos, em busca de uma aprendizagem significativa. (AGUIAR, 1999).

Nessa ideia de Laboratório de Ensino de Matemática, entendida como um processo, a construção do conhecimento se dá de forma dialética, havendo sempre a mediação do professor entre o objeto a ser conhecido e o sujeito (aluno). Durante o desenvolvimento desse processo, cabe ao professor oportunizar aos alunos momentos de reflexão durante a interação destes com o objeto a ser conhecido, de forma que experiências individuais de formação e transformação possam surgir de forma significativa para cada um. (LARROSA, 2002). Nesse contexto, segundo Lorenzato (2006), os materiais didáticos “criam vida" à medida que dinamizam e enriquecem as atividades de ensino-aprendizagem. Sendo assim, é recomendável que os mesmos sejam utilizados como um meio auxiliar do processo de ensino-aprendizagem (LORENZATO, 2006) e não como um objeto material com finalidade em si mesmo, conforme se verifica na caracterização do Laboratório Tradicional (Laboratório de Matemática).

Passos (2006) alerta que este laboratório não deve ficar somente restrito a "lugar", ou "processo", mas deve incluir ainda "atitude". (PASSOS, 2006, p.90). De acordo com essa autora, a ideia é proporcionar ao aluno maior autonomia de pensamento, de modo que este seja capaz de observar, refletir e questionar por si mesmo. Nesse sentido, a autora exalta a grande importância do laboratório no desenvolvimento de atitudes ligadas à formação do perfil investigativo do aluno, possibilitando um contato mais próximo do mesmo com a Matemática, aumentando, assim, a sua perseverança na busca de soluções e sua confiança na sua capacidade de aprender e investigar.

Toda essa descrição da sala ambiente como um lugar e um processo, capaz de gerar atitudes positivas em relação à construção do conhecimento matemático vai ao encontro das ideias descritas em relação ao ambiente construtivista de aprendizagem proposto e caracterizado por Valadares (2001).

Em relação à utilização deste tipo de laboratório nas instituições de Ensino Superior, Lorenzato (2006) ressalta a importância do mesmo, como um local para a realização da prática pedagógica do acadêmico durante a sua formação inicial. Segundo ele, é neste ambiente que os futuros professores deverão aprender a utilizar corretamente os materiais de 
ensino. Complementando as ideias de Lorenzato (2006), Lopes e Araújo (2007) consideram que o objetivo desse laboratório num curso de Licenciatura em Matemática é propiciar ao futuro professor "o conhecimento e a vivência de metodologias alternativas para o ensino e a aprendizagem da Matemática” (LOPES; ARAÚJO, 2007, p.60).

\section{7) Laboratório/ Agente de formação - Laboratório de Educação Matemática}

O Laboratório descrito aqui como "Agente de formação" (TURRIONI, 2004) engloba a concepção de sala ambiente (Laboratório de Ensino de Matemática) discutido anteriormente, como também abarca outras ideias propostas por: Rêgo e Rêgo (2006), Oliveira (1983), Lopes e Araújo (2007), Turrioni (2004). Este tipo de laboratório, entendido também como "Laboratório de Educação Matemática", tem como foco central a realização de atividades de ensino, pesquisa e extensão com ênfase na formação inicial e continuada de professores em Matemática.

De acordo com Turrioni (2004), esta concepção de laboratório engloba também uma nova função:

[...] constituir-se num ambiente que funciona como um centro para discussão e desenvolvimento de novos conhecimentos dentro de um curso de licenciatura em Matemática, contribuindo tanto para o desenvolvimento profissional dos futuros professores como para sua iniciação em atividades de pesquisa. (TURRIONI, 2004, p.62).

A autora entende que, diante dessa proposta, o laboratório deve ser entendido como um "agente de mudança num ambiente onde se encontram esforços de pesquisa na busca de novas alternativas para o aperfeiçoamento do curso de Licenciatura em Matemática, bem como do currículo dos cursos de Ensino Fundamental e Médio.” (TURRIONI, 2004, p.64). Nesse sentido, as atividades desenvolvidas por meio da metodologia de projetos deverão ser fundamentais nesse ambiente "para que o aluno futuro-professor possa se desenvolver profissionalmente e fazer pesquisa." (TURRIONI, 2004, p.66).

$\mathrm{Na}$ tentativa de tornar mais amplo o campo de atuação desse laboratório, encontramos em Lopes e Araújo (2007) uma proposta para a utilização do Laboratório de Educação 
Matemática, tanto na formação inicial de professores quanto na formação continuada. Nessa proposta, o laboratório aparece como:

-Órgão de assessoria didático-pedagógica ao curso de Licenciatura em Matemática.

-Órgão de prestação de serviços à universidade e à comunidade.

-Órgão de pesquisa visando à qualidade do ensino da Matemática. (LOPES; ARAÚJO, 2007).

Como órgão de assessoria didático-pedagógica ao curso de Licenciatura em Matemática, Lopes e Araújo (2007) explicam que o laboratório deverá "atuar no sentido de elevar o nível de desempenho dos acadêmicos, contribuindo para o seu desenvolvimento profissional". (LOPES; ARAÚJO, 2007, p.61).

Nesse sentido, a realização de atividades envolvendo a construção e a utilização de material didático, a vivência de metodologias de ensino alternativas como: a modelagem matemática, atividades de exploração e investigação, a vivência de projetos interdisciplinares, a resolução de problemas e o uso das tecnologias de informação e comunicação aliadas a uma postura construtivista do professor poderão tornar o ensino e a aprendizagem da Matemática mais agradável e eficiente no ambiente do laboratório.

Já como órgão de prestação de serviço, este deverá capacitar professores, oferecendo cursos como, por exemplo: palestras, oficinas e mini-cursos (LOPES; ARAÚJO, 2007). Dessa forma, as atividades desse laboratório ganhariam maior alcance social à medida que os professores e alunos da Educação Básica pudessem ter a oportunidade de experimentar materiais didáticos alternativos, bem como novas propostas de ensino, aulas de reforço escolar, monitoria, palestras, cursos de capacitação e participação em grupos de pesquisa e trabalho colaborativo. Essa parceria entre a comunidade e a instituição formadora é também uma característica dessa proposta de laboratório.

Como órgão de pesquisa, segundo os autores, ele deverá incentivar a formação de grupos de pesquisa voltados para o ensino da Matemática, bem como impulsionar a realização de projetos de iniciação científica. (LOPES; ARAÚJO, 2007).

Nesse contexto, poderão ser propostos estudos e pesquisas na área de Educação Matemática com o intuito de identificar os problemas educacionais enfrentados pela comunidade escolar 
existente neste local. Essa vivência da pesquisa educacional no ambiente do Laboratório de Educação Matemática permite o desenvolvimento da postura investigativa, reflexiva e crítica do aluno em formação, devendo este, por si só, através da prática da pesquisa, tornar-se um agente capaz de buscar a solução para os problemas enfrentados em sala de aula.

Nessa mesma direção, Rêgo e Rêgo (2006) explicam que o papel deste laboratório, quando instalado em instituições de Ensino Superior é incentivar a melhoria da formação inicial e continuada de professores, promovendo ações que visam à integração das áreas de ensino, pesquisa e extensão, como, também, favorecer o estreitamento da relação entre a instituição e a comunidade, além de estimular a prática da pesquisa em sala de aula.

De acordo com Oliveira (1983), esse laboratório deverá proporcionar situações para a realização da pesquisa à medida que:

\footnotetext{
- promover o aperfeiçoamento dos currículos de $1^{\circ}, 2^{\circ}$ e $3^{\circ}$ graus ${ }^{7}$;

- buscar novas metodologias aplicadas a casos específicos e

-garantir uma generalização de determinadas conclusões ou, pelo menos, garantir a adequação do ensino à realidade da comunidade. (OLIVEIRA, 1983, p.92).
}

Por fim, a autora considera que esse laboratório será de extensão "na medida em que proporcionar oportunidade a todos os professores da comunidade, de participação no processo de pesquisa." (OLIVEIRA, 1983, p.92). Ainda de acordo com a autora, essa participação poderá acontecer da seguinte forma:
a) na testagem de uma nova metodologia;
b) na avaliação de objetivos;
c) na contribuição com suas experiências e no intercâmbio das mesmas com os alunos do curso de Licenciatura;
d) na participação de cursos de aperfeiçoamento propostos pelo laboratório para atender às necessidades da mesma comunidade. (OLIVEIRA, 1983, p.92-93).

\section{Conclusão}

A partir desse estudo, verifica-se por meio da caracterização do laboratório denominado "Agente de formação" que este apresenta uma concepção mais ampla de laboratório, sugerindo, portanto, maiores contribuições para a formação de professores. A partir da caracterização deste laboratório foi possível delinear o seu perfil e verificar suas contribuições para a formação de professores, sintetizado no quadro a seguir: 
Quadro 1: Caracterização do Laboratório Agente de Formação

\begin{tabular}{|c|c|c|}
\hline \multicolumn{3}{|c|}{ Laboratório de Educação Matemática } \\
\hline \multicolumn{2}{|c|}{ Tipo de Laboratório } & -Agente de formação \\
\hline \multicolumn{2}{|c|}{ Atuação } & -Formação inicial e continuada de professores \\
\hline \multicolumn{2}{|c|}{ Público alvo } & $\begin{array}{l}\text {-Acadêmicos e professores do curso de Licenciatura em } \\
\text { Matemática. } \\
\text {-Alunos e professores das escolas públicas. } \\
\text {-Comunidade acadêmica e comunidade externa. }\end{array}$ \\
\hline $\begin{array}{l}\text { Características } \\
\text { do ambiente }\end{array}$ & Lugar & $\begin{array}{l}\text {-Lugar para experimentar a prática pedagógica. } \\
\text {-Estudo, discussão, investigação, produção e difusão do } \\
\text { conhecimento. } \\
\text {-Agradável e prazeroso. } \\
\text {-Lugar para tornar a Matemática mais próxima da realidade. } \\
\text {-Convivência, interação e troca de experiências. } \\
\text {-Lugar para atender às necessidades formativas dos } \\
\text { acadêmicos. } \\
\text {-Espaço de pesquisa e produção científica. }\end{array}$ \\
\hline \multirow{2}{*}{$\begin{array}{c}\text { Ambiente } \\
\text { Construtivista } \\
\text { de Aprendizagem }\end{array}$} & Processo & $\begin{array}{l}\text {-Ambiente para estruturar, organizar, planejar e fazer } \\
\text { acontecer o pensar matemático. } \\
\text {-Ambiente que facilita professores e alunos a conjecturar, } \\
\text { experimentar, analisar, concluir, aprender, aprender a } \\
\text { aprender. } \\
\text {-Aprender a fazer fazendo. } \\
\text {-Desenvolver competências e habilidades. } \\
\text {-Criação e descoberta. } \\
\text {-Reflexão na ação. } \\
\text {-Interação. }\end{array}$ \\
\hline & Atitude & $\begin{array}{l}\text {-Indagação. } \\
\text {-Procura. } \\
\text {-Criatividade. } \\
\text {-Mudança de atitude frente ao ensino tradicional. } \\
\text {-Despertar a aprendizagem crítica. } \\
\text {-Estimular o desenvolvimento de habilidades sociais. } \\
\text {-Despertar o interesse pelo estudo da Matemática. } \\
\text {-Contribuir para o desenvolvimento de atitudes relacionadas } \\
\text { ao hábito de frequentar a universidade para estudar e } \\
\text { socializar o conhecimento. }\end{array}$ \\
\hline \multicolumn{2}{|c|}{ Característica das atividades } & $\begin{array}{l}\text {-Interdisciplinar, contextualizada. } \\
\text {-Desenvolvidas por meio de projetos. }\end{array}$ \\
\hline \multicolumn{2}{|c|}{ Metodologia de trabalho } & $\begin{array}{l}\text {-Trabalho colaborativo. } \\
\text {-Uso da metodologia de projetos. } \\
\text {-Montagem de grupos de estudos. }\end{array}$ \\
\hline \multicolumn{2}{|l|}{ Papel do professor } & -Mediador. \\
\hline \multicolumn{2}{|l|}{ Utilização de MD } & $\begin{array}{l}\text {-Meio auxiliar do processo ensino-aprendizagem. } \\
\text { (Ressalta-se a importância da ação reflexiva, mediada pelo } \\
\text { professor durante a utilização dos materiais didáticos) }\end{array}$ \\
\hline
\end{tabular}

Fonte: Dados da pesquisa 


\section{Referências}

AGUIAR, Marcia. Uma idéia para o Laboratório de Matemática. 1999. 216f. Dissertação (Pós-graduação em Educação) Faculdade de Educação da Universidade de São Paulo. São Paulo - SP. Orientador: Nilson José Machado. 1999.

BENINI, M.B.C. Laboratório de Ensino de Matemática e Laboratório de Ensino de Ciências: uma comparação. 2006. 108f. Dissertação (Pós-graduação em Ensino de Ciências e Educação Matemática) Universidade Estadual de Londrina, Londrina -PR. Orientador: Dr. Carlos Eduardo Laburú. 2006.

BERTONI, N.E.; GASPAR, M.T.J. Laboratório de ensino de Matemática da Universidade de Brasília - uma trajetória de pesquisa em Educação Matemática, apoio à formação do professor e interação com a comunidade. In: LORENZATO, Sérgio (Org). Laboratório de Ensino de Matemática na formação de professores. Campinas: Autores Associados, 2006. p.135-152.

FIORENTINI, D.; LORENZATO, S. Investigação em educação matemática: percursos teóricos e metodológicos. Campinas: Autores associados, 2006.

KALEFF, A.M.M.R. Do fazer concreto ao desenho em geometria: ações e atividades desenvolvidas no laboratório de ensino de geometria da Universidade Federal fluminense. In: LORENZATO, Sérgio. Laboratório de Ensino de Matemática na formação de professores. Campinas: Autores Associados, 2006. p.113-134.

LABURÚ, Carlos Eduardo. Seleção de experimentos de Física no Ensino Médio: uma investigação a partir da fala dos professores. 2005. Disponível em: <http://www.if.ufrgs.br/ public/ensino/vol10/n2/v10_n2_a2.htm>. Acesso em: 13 dez. 2009.

LARROSA, Jorge. Notas sobre a experiência e o saber da experiência. Revista Brasileira de Educação. São Paulo: Associação Nacional de Pós-Graduação e Pesquisa em Educação, n.19, jan./abr, 2002. p.20-28.

LOPES, J. A. ARAUJO, E. A. O Laboratório de Ensino de Matemática: implicações na formação de professores. Revista Zetetiké. Cempem: Unicamp, v.15, n.27, jan./jun. - 2007. p.57-69.

LORENZATO, S. Laboratório de ensino de matemática e materiais didáticos manipuláveis. In: LORENZATO, Sérgio. Laboratório de Ensino de Matemática na formação de professores. Campinas: Autores Associados, 2006. p.3-38.

MISKULIN, R.G.S. As potencialidades didático-pedagógicas de um Laboratório em Educação Matemática mediado pelas TICs na formação de professores. In: LORENZATO, Sérgio. Laboratório de Ensino de Matemática na formação de professores. Campinas: Autores Associados, 2006. p.153-178. 
NUNES, E.L.V.; SOUZA, J.A.; DANDOLINI, G.A. Laboratório de Ensino de Matemática a Distância. Novas Tecnologias na Educação. v.3, n.1, Maio, 2005. p.1-7.

OLIVEIRA, A.M.N. Laboratório de Ensino e Aprendizagem em Matemática: as razões de sua necessidade. 1983. 188f. Dissertação (Pós-graduação em Educação) Universidade Federal do Paraná, Curitiba, PR. Orientador: Lauro da Silva Becker. 1983.

OTTESBACH,R.C.; PAVANELLO, R.M. Laboratório de Ensino e Aprendizagem da Matemática na apreciação de professores, 2009. Disponível em: www.diaadiaeducacao.pr.gov.br/portals/pde/arquivos/248-4.pdf. Acesso em: 28 dez. 2010.

PASSOS, C.L.B. Materiais manipuláveis como recursos didáticos na formação de professores de matemática. In: LORENZATO, Sérgio. Laboratório de Ensino de Matemática na formação de professores. Campinas: Autores Associados, 2006. p.77-92.

PASSOS, C.L.B. et al. O Laboratório de Ensino de Matemática na atuação e na formação inicial de professores de Matemática. In: COLE, 16, 2007, Campinas. Anais... Campinas: ALB, 2007. p.1-10.

PIRES, A.M.M. O Lema na formação inicial do educador matemático, na universidade de Guarulhos, 2008. Disponível em:

http://www.sbem.com.br/files/ix enem/Comunicacao_Cientifica/Trabalhos/CC52243893800 T.doc. Acesso em: 29 dez. 2010.

REFOSCO, M.I.; BASSOL, T.S. O Laboratório de Ensino de Matemática nas escolas públicas do Paraná e as concepções dos professores, 2007. Disponível em:

www.diaadiaeducacao.pr.gov.br/portals/pde/arquivos/847-4.pdf. Acesso em: 29 dez. 2010.

RÊGO, R.M.; RÊGO, R.G. Desenvolvimento e uso de materiais didáticos no ensino de matemática. In: LORENZATO, Sérgio. Laboratório de Ensino de Matemática na formação de professores. Campinas: Autores Associados, 2006. p.39-56.

SCHEFFER, N.F. O LEM na discussão de conceitos de geometria a partir das mídias: dobradura e software dinâmico. In: LORENZATO, Sérgio. Laboratório de Ensino de Matemática na formação de professores. Campinas: Autores Associados, 2006. p.93-112.

SOLETIC, A. A produção de materiais escritos nos programas de Educação a distância: Problemas e desafios. In: LITWIN, Edith (Org). Educação a Distância: temas para o debate de uma nova agenda educativa. Trad. Fátima Murad. Porto Alegre: Ed. Artmed, 2001.

TAHAN, M. Didática da Matemática. São Paulo: Ed. Saraiva. v.2, 1962.

TURRIONI, A.M.S. O Laboratório de Educação Matemática na formação inicial de professores. 2004. 168f. Dissertação (Pós-graduação em Educação Matemática e seus fundamentos Filosóficos-Científicos) Universidade Estadual Paulista, Rio Claro-SP. Orientador: Geraldo Perez. 2004. 
TURRIONI, A.M.S.; PEREZ,G. Implementando um laboratório de educação matemática para apoio na formação de professores. In: LORENZATO, Sérgio. Laboratório de Ensino de Matemática na formação de professores. Campinas: Autores Associados, 2006. p.57-76.

VALADARES, J. Estratégias construtivistas e investigativas no ensino das Ciências, 2001, Lisboa: Universidade Aberta. Disponível em: http://eec.dgidc.minedu.pt/documentos/publicacoes_estrat_const.pdf. Acesso em: 28 dez. 2010.

VARIZO, Z.C.M. O Laboratório de Educação Matemática do IME/UFG: Do sonho a realidade. In: ENEM, 10, 2007, Belo Horizonte. Anais... Belo Horizonte, 2007. p.1-12. 